CYTOMEGALOVIREMIA IN HEALTHY ASYMPTOMATIC PREGNANT

ADOLESCENTS, David J. Lang, John F. Kummer, Sherrie E. 2weig and Mary J. Lang, City of Hope Medical Center, Div. of Pediatrics, Duarte California 91010.

Based upon clinical observations it has been deduced that human cytomegalovirus (HCMV) may be transmitted with blood. It has been estimated that approximately 58 of healthy individuals are asymptomatic carriers of HCMV in blood. 列 in immunosuppressed individuals or from those with symptomatic HCMV-associated clinical conditions, efforts to recover virus from the blood of asymptomatic healthy carriers have been largely and repeatedly unsuccessful. Only one report has documented viremia in healthy individuals (in 1969 Diosi and associates reported recovery of HCMV from blood in 2 of 35 blood bank donors). In the course of studies of healthy pregnant adolescents in North Carolina and in Maryland, HCMV was recovered from the blood in 5 of 96 and 2 of 41 subjects respectively, or 58 in each population. There was no demonstrable association with prenatal transmission of HCMV, with subject well-being or outcome of pregnancy.gThe risk of $\mathrm{HCMV}$ reactivation in young pregnant women may relate to gestational and endocrine factors. It is also possible that reactivation of HCMV occurs most frequently soon after primary infection and that the risk of reactivation is inversely related to the elapsed time since virus acquisition. These observations may assist in defining risk factors for transfusion-related transmission as well as for reactivation and prenatal acquistion of HCMV. DETECTION OF MEASLES IgM. Alan W. Lievens, Philip A.
Brunell, and Elaine K. Cobb. U.T. Health Science

1105 Center, Department of Pediatrics, San Antonio, Texas. the number of cases continues to decline. For this reason an the number of cases continues to decline. For this reason an
Enzyme Linked Immunosorbent Assay (ELISA) was developed to detect measles virus specific IgM antibody (MIgMA). Anti-human $\mu$ chain is affixed to a solid phase to which a $1: 100$ dilution of serum is added. Only $0.005 \mathrm{ml}$ of patient's serum is needed. Treatment of 3 MIgMA positive sera with dithiothreitol but not Staph protein A removed MIgMA. The values for 24 cord sera $(0.030+0.007), 60$ adult sera $(0.034+0.011)$, and 47 sera from children prior to measles immunization $(0.030+0.015)$ were used to establish a seronegative range. Sera yielding reactions greater than 3 SD of the mean for the latter group were considered to be positive for the presence of MIgMA. MIgMA was not detected in sera with high titers of rheumatoid factor. Five unpaired and the first of 14 of 17 paired sera obtained from patients with measles were positive for MIgMA. The 3 convalescent samples from patients having MIgMA negative initial sera, also were positive. MIgMA was detected as early as 1 day and as late as 41 days following onset of illness. No MIgMA and as late as 41 days following onset of 111 ness. No MIgMA after measles vaccination. Neither recent immunization nor the presence of rheumatoid factor produce reactions which are likely to obfuscate the interpretation of this very sensitive test which, in most cases, can confirm the clinical diagnosis of measles on a single serum specimen obtained soon after onset of rash.

DEGENERATIVE CHANGES IN NEUTROPHILS-AN INDICATOR OF

1106 BACTERIAL INFECTION. Cheng-Hurd Liu, Carol Lehan, Michael E. Speer, Donald J. Fernback, Arnold J. Rudolph. Baylor College of Medicine, Department of Pediatrics, Houston, Texas. (Spon. by Thomas N. Hansen)

In 157 neonates in whom a sepsis work-up was performed, 195 peripheral blood smears were reviewed. Neutrophil degenerative changes (vacuolization and toxic granulation) were seen frequently in culture proven bacterial sepsis. Seventeen of 21 peripheral blood smears from neonates subsequently proven to have bacterial infection had vacuolization in neutrophils for a sensitivity of $81 \%$, specificity of $93 \%$ and positive predictive accuracy of $59 \%$. Comparison of relative values for
predicting neonatal bacterial infection utililizing five items from a single blood sample are shown in the table:

\begin{tabular}{|c|c|c|c|c|c|}
\hline & $\begin{array}{l}\text { Vacuoli- } \\
\text { zation }\end{array}$ & $\begin{array}{l}\text { Toxic } \\
\text { Granu- } \\
\text { lation }\end{array}$ & $\begin{array}{l}\text { Band/Tota] } \\
\text { Neutrophi } 1 \\
\geqslant 0.2\end{array}$ & 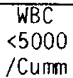 & $\begin{array}{c}\text { Platelet } \\
<150,000 \\
\text { /Cumm }\end{array}$ \\
\hline $\begin{array}{l}\text { TotaT }(+) \text { Test } \\
(+) \text { Test with }\end{array}$ & 29 & 31 & 54 & 22 & 40 \\
\hline Proven Sepsis & 17 & 14 & 14 & 6 & 8 \\
\hline Sensitivity & $81 \%$ & $67 \%$ & $67 \%$ & $29 \%$ & $38 \%$ \\
\hline $\begin{array}{l}\text { Specificity } \\
(+) \text { Predict. }\end{array}$ & $93 \%$ & $90 \%$ & $77 \%$ & $91 \%$ & $82 \%$ \\
\hline Accuracy & $59 \%$ & $45 \%$ & $26 \%$ & $27 \%$ & $20 \%$ \\
\hline
\end{tabular}

found in the peripheral blood smear of neonates with bacter$i$ al infection and appear to be more reliable indicators of septicemia than traditional tests.
THE USE OF HOMOLOGOUS AND HETEROLOGOUS

$\$ 1107$ ROTAVIRUS ANTIBODIES FOR THE PREVENTION OF ROT AVIRUS GASTROENTERITIS. Genevieve A. Losonsky,
Joseph Eiden, Steve Vonderfecht, Robert Yolken, Dept. of Pediatrics and Comparative Medicine, Johns Hopkins School of Medicine, Baltimore, Maryland.

Rotavirus is an important cause of serious gastroenteritis in children. One possible strategy for the prevention of rotavirus gastroenteritis is the oral administration of rotavirus specific immunoglobulin. We utilized a mouse model of rotavirus infection to examine the efficacy of rotavirus antibody for the prevention of symptomatic rotavirus diarrhea. This model consists of the feeding of seronegative infant mice a predetermined amount of murine rotavirus and antibody and then assaying the animals for intestinal antigen excretion, liquid colonic contents, and immune response. We found that mouse serum containing homologous antibodies to murine rotavirus completely protected animals from symptomatic infection and viral shedding while non-immune serum provided no protection. Neither immune nor non-immune mouse milk offered any protection from infection. In the case of heterologous sources of sera obtained from animals experimentally infected with sources of sera obtained from animals experimentally infected with
human or bovine rotaviruses, and antibodies derived from the yolks of human or bovine rotaviruses, and antibodies derived from the yolks of
eggs obtained from chickens immunized with rotaviruses full protection eggs obtained from chickens immunized with rotaviruses full protection human milk did not protect the animal from infection. The majority of the animals treated with effective specific immunoglobulin preparations developed a rotavirus systemic antibody response. These studies indicate that homologous and heterologous sources of rotavirus antibodies can provide protection from rotavirus diarrhea and may allow for active immunity to occur.

\section{IMMUNOLOGIC STUDIES OF ENTERIC CORONAVIRUS-LIKE}

1108 PARTICLES (CVLP). Mary E. Lund, C. George Ray, Claire Departments of Pediatrics and Pathology, Tucson.

CVLP have been implicated in gastrointestinal illness sporadically among children and in an intensive care nursery outbreak at our hospital. Fecal examination by electron microscopy(EM) is the only means of diagnosis. We developed an enzyme-linked immunosorbent assay(ELISA) using ammonium sulfate precipitated CVLP from feces. The purified CVLP was immunogenic in rabbits. Sera containing antibodies against bovine enteric, canine, 0C43, and $229 \mathrm{E}$ coronaviruses(CV) did not block binding of rabbit anti-CVLP to microtiter wells coated with purified CVLP. Immune EM using these antisera and nonaggregated CVLP also suggested that CVLP are antigenically distinct from other CV. False positives occurred when stools negative for CVLP by EM were tested. This nonspecific reaction was not blocked by sonicates of E.coli, Strep. fecalis, B.fragilis, or C.difficile, or by C.difficile antitoxin. Absorption of rabbit anti-CVLP serum with suckling mouse intestine did not improve specificity. More sophisticated purification of fecal CVLP is needed to improve ELISA sensitivity and specifictity, and to characterize the antigen.
119 INAPPARENT INTRAUTERINE HSV INFECTION DETECTED BY 1109 Kurt Benirschke (Spon. by Louis Gluck) Univ. of Calif San Diego, Depts. of Ped. \& Pathol. La Jolla, CA \& Green Hospital of Scripps Clinic (Pathol), La Jolla, Calif.

We have used glucose oxidate-avidin-biotin (GAB) immunohistochemistry to detect herpes simplex virus (HSV) I \& 2 virion antigen in fixed tissue. Cases were selected by placental or cord pathology $\varepsilon / o r$ clinical findings in the fetus/neonate. Virus was detected in placenta, umbilical cord $\varepsilon / o r$ fetal/infant organs from 17 pregnancies ( 1 set twins; 15 newborns \& 3 stillborns). Antigen was found in single mesenchymal $\varepsilon$ epithelial cells without characteristic viral cytopathology. Viral cultures were positive in one case (skin vesicles). Five mothers had clinical or laboratory evidence of HSV $1 / 2$ infections before or during pregnancy, but none had evidence of active infection at delivery. Thirteen pregnancies ended prematurely \& 5 infants/fetuses were small for gestational age. Ten newborns were severely ill. Four infants died before $7-1 / 2$ months of age. of 11 survivors, 2 have severe CNS abnormalities, 1 persistent pulmonary disease $\& 2$ remain CNS abnormalities, 1 persistent pulmonary disease $\& 2$ remain
hospitalized. Diagnoses associated with GAB positive herpes hospitalized. Diagnoses associated with GAB positive herpes
virus in specific organs include NEC, hepatitis with cholestatic jaundice, interstitial pneumonitis, aseptic meningitis, progres sive cystic brain degeneration, $\varepsilon$ cardiac arrhythmias. We conclude that intrauterine HSV infection is more common than believed \& that intrauterine HSV infection may persist in the fetus $\&$ neonate chronically without cytopathology or detectable virus $\varepsilon$ may be associated with prematurity, intrauterine $\&$ neonatal death, organ damage, $\varepsilon$ progressive neonatal disease. 